\title{
PENGEMBANGAN DAN PEMANFAATAN MULTIMEDIA DALAM PEMBELAJARAN INTERAKTIF
}

\section{THE DEVELOPMENT AND UTILIZATION OF MULTIMEDIA FOR INTERACTIVE LEARNING}

\author{
Mohamad Miftah \\ Bappeda Propinsi Jawa Tengah \\ Email : hasanmiftah@yahoo.com
}

Naskah Masuk: 8 Mei 2018

Naskah Revisi: 10 Oktober 2018

Naskah Diterima: 16 Oktober 2018

\begin{abstract}
On the one hand, the development of information and communication technology especially in education sector grows fastly. On the other hand, in practice, the utilization of this technology shows lower results. The objective of this study is to describe the role of interactive learning by using multimedia and the utilization of multimedia in learning activities. Desk research is used as design of this research and it use qualitative approach. Data mainly are collected from the literature and analyzed descriptively. The findings show that the application of multimedia plays an important role to improve the quality of teaching and learning activities. Later, the development of information and communication technology offers various types of interactive learning and the multimedia has the potential to attrach students to involve in learning activity as well as to increase learning outcomes. Finally, there is a neccessity to accelerate the development of human resources in particular teachers so that the utilization of the technology run optimally.
\end{abstract}

Keywords: multimedia, interactive learning, information and communication technology

\begin{abstract}
ABSTRAK
Pada satu sisi, perkembangan teknologi informasi dan komunikasi khususnya di dunia pendidikan berkembang dengan cepat. Namun di sisi lain, realitanya pemanfaatan multimedia pembelajaran interaktif masih terbilang rendah. Penelitian bertujuan untuk memberikan gambaran mengenai peran media pembelajaran berbasis komputer sekaligus pengembangan dan pemanfaatannya dalam kegiatan belajar mengajar. Desain penelitian yang digunakan adalah desk research dengan pendekatan kualitatif. Data penelitian diperoleh melalui studi literatur dan selanjutnya data dianalisis secara deskriptif. Hasil penelitian menunjukkan bahwa penggunaan multimedia sebagai media pembelajaran dapat memberikan kontribusi yang besar untuk meningkatkan kualitas kegiatan belajar mengajar. Perkembangan produk-produk teknologi informasi komunikasi menawarkan berbagai bentuk media pembelajaran yang variatif sekaligus efektif dalam menarik minat peserta didik untuk belajar yang pada akhirnya mampu meningkatkan hasil belajar siswa. Penyiapan sumber daya manusia khususnya pengajar yang handal menjadi faktor penting agar pemanfaatan multimedia sebagai media pembelajaran interaktif dapat berlangsung secara optimal.
\end{abstract}

Kata kunci : multimedia, pembelajaran interaktif, teknologi informasi dan komunikasi.

\section{PENDAHULUAN}

Kemajuan di bidang teknologi pendidikan (educational technology), maupun teknologi pembelajaran (instructional technology) menuntut digunakannya berbagai media pembelajaran (instructional media) serta peralatan-peralatan yang semakin canggih. Boleh dikatakan bahwa dunia pendidikan dewasa ini hidup dalam dunia media. Kegiatan pembelajaran mulai beralih dari sistem penyampaian bahan pengajaran dengan metode ceramah dan berganti dengan penggunaan multimedia. Lebih-lebih pada kegiatan pembelajaran yang lebih menekankan pada kompetensi-kompetensi yang terkait dengan keterampilan proses, maka peranan media pembelajaran menjadi diperlukan. 
Pembelajaran yang dirancang secara baik dan kreatif dengan memanfaatkan multimedia, dalam batas-batas tertentu akan dapat memperbesar kemungkinan siswa untuk belajar lebih banyak, memahami apa yang dipelaja-rinya, dan meningkatkan kemampuan (performance) siswa dalam rangka meningkatkan ketercapaian kompetensi. Pembelajaran yang berlaku pada abad ini bukan lagi siswa menunggu materi dari guru, melainkan siswa mencari sendiri sumber belajarnya (Suryo, 2013). Arah pendekatan pembelajaran inovatif adalah belajar dan mengajar menggunakan teknologi. Namun potensi ini kurang didukung pemegang kewenangan dan pihak sekolah dalam mengoptimalkan pemanfaatan media pembelajaran berbasis komputer.

Kualitas pendidikan sangat ditentukan oleh kemampuan sekolah dalam mengelola proses pembelajaran. Khususnya pada proses pembelajaran yang terjadi di kelas. Pembelajaran berbasis komputer (PBK) dimaksudkan adalah model atau produk pembelajaran yang secara sengaja didesain dan dikembang-kan dengan menggunakan komputer sebagai basis guna memudahkan proses belajar.

Saat ini masih dijumpai beberapa permasalahan dalam pembelajaran di kelas. Sebagian guru belum maksimal menggunakan dan mengembangkan media pembelajaran berbasis komputer pada kegiatan belajar mengajar (KBM). Multimedia yang dimaksud dalam tulisan ini tidak semata-mata penggunaan berbagai media namun mensyaratkan atau identik dengan multimedia yang berbasis komputer yang dikembangkan secara layak untuk dimanfaatkan. Pemanfaatan multimedia dalam pembelajaran dirasa hanya berlangsung di sekolah-sekolah favorit yang memiliki sarana prasarana yang lengkap dengan kualitas pengajar yang tinggi. Padahal pemanfaatan media pembelajaran dapat diterapkan kapan dan dimanapun.
Berdasarkan permasalahan di atas, dapat diketahui bahwa; masih minimnya sebagian guru/tenaga pendidik yang memanfaatkan teknologi informasi dan komunikasi (TIK) dalam KBM dengan benar dan masih banyak terdapat guru yang belum mampu mengembangkan media pembelajaran berbasis komputer. Penelitian dilakukan dengan tujuan memberikan gambaran mengenai pengembangan dan pemanfaatan multimedia dalam pembelajaran interaktif. Diharapkan, para pihak terkait terutama para pendidik dapat memanfaatkan kemajuan teknologi informasi dan komunikasi dalam KBM di kelas. Sehingga pada akhirnya dapat meningkatkan penguasaan siswa terhadap materi pelajaran dan meningkatkan hasil belajar peserta didik.

\section{TINJAUAN PUSTAKA}

\section{Pengertian Media Pembelajaran}

Pengertian media secara umum dari segi teori komunikasi memberikan batasan secara khusus tentang media pembelajaran. Association for Education and Communication Technology (AECT), mengartikan media sebagai segala bentuk dan saluran yang dipergunakan untuk proses informasi. National Education Association (NEA) mendefinisikan media sebagai segala benda yang dapat dimanipulasi, dilihat, didengar, dibaca atau dibicarakan beserta instrumen yang dipergunakan untuk kegiatan tersebut (Seels \& Richey, 2013). Sedangkan Heinich, dkk (2010) mengartikan istilah media sebagai "the term refer to anything that carries information between a source and a receiver".

Sementara kegiatan pembelajaran adalah suatu proses komunikasi. Artinya kegiatan belajar melalui media terjadi bila ada komunikasi antara penerima pesan $(\mathrm{P})$ dengan sumber (S) lewat media (M) tersebut. Namun proses komunikasi itu sendiri baru terjadi setelah ada reaksi balik (feedback). 
Kata media berasal dari bahasa latin dan merupakan bentuk jamak dari kata medium yang secara harfiah berarti perantara atau pengantar (Sadiman, dkk 2012). Jadi media adalah perantara atau pengantar pesan dari pengirim kepada penerima pesan. Seels \& Richey (2013) memberi batasan media sebagai segala bentuk dan satuan yang digunakan untuk mengeluarkan pesan dan informasi.

Media dalam proses komunikasi merupakan saluran komunikasi yang menghubungkan antara pesan ke penerima pesan. Walter et al. (2005) menyatakan bahwa media disebut juga perangkat lunak "software" yang berisikan pesan untuk disampaikan dengan menggu-nakan peralatan. Menurut Latuheru (2012) sesuatu dapat dikatakan sebagai media pembelajaran, apabila media tersebut digunakan untuk menyam-paikan pesan dengan tujuan pembelajaran.

Jadi media pembelajaran itu merupakan wahana penyalur pesan atau informasi belajar. Miarso (2010) memberikan batasan media pembelajaran sebagai segala sesuatu yang dapat digunakan untuk merangsang fikiran, perasaan, perhatian dan kemauan siswa sehingga dapat mendorong terjadinya proses belajar pada diri siswa. Batasan yang sederhana ini, menurut Prastati \& Irawan (2010) memiliki arti yang sangat luas dan mendalam, mencakup pengertian sumber, lingkungan, manusia dan metode yang dimanfaatkan untuk tujuan pembelajaran. Jadi pengertian media pembelajaran adalah: (a) media merupakan wadah dari pesan yang oleh sumber atau penyalurnya ingin diteruskan kepada sasaran atau penerima pesan tersebut; (b) bahwa materi yang ingin disampaikan adalah pesan pembelajaran; dan (c) bahwa tujuan yang ingin dicapai adalah terjadinya proses belajar.

\section{Sistem Multimedia Interaktif}

Terkait teknis penyimpanan informasi pada sistem multimedia, Arsyad (2012) membagi jenis multimedia menjadi: 1). Sistem multimedia stand alone, maksudnya sistem ini berarti merupakan sistem multimedia yang memiliki minimal storage (harddisk, CDrom, DVD, dll) atau alat input dan outputmisalnya CD interaktif, DVD movie, handphone dan kamera digital; 2). Sistem multimedia berbasis jaringan, maksudnya sistem ini harus terhubung dengan jaringan yang memiliki bandwith besar.

Menurut Sandiman, dkk (2012) multimedia ditinjau dari sasaran pengguna dapat dikategorikan dalam: (1). Multimedia content production, artinya bahwa multimedia yang menghasilkan produk kreatif berupa konten musik, film, permainan, hiburan, dll; (2). Multimedia communication, artinya penggunaan sejumlah teknologi yang berbeda dengan tujuan untuk komunikasi atau media massa, seperti media televisi, radio, cetak, dan internet. Jadi sistem multimedia pada prinsipnya adalah kombinasi dari media dasar audio visual dan visual yang dipergunakan untuk tujuan pembelajaran dan penggunaan secara kombinasi dua atau lebih media pembelajaran ini yang dikenal dengan sistem multimedia.

\section{Peran dan Fungsi Media Pembelajaran}

Dewasa ini masih banyak guru-guru yang enggan memanfaatkan media yang ada untuk kegiatan pembelajaran. Masih banyak kecenderungan para siswa dibiasakan untuk mendengarkan apa yang diajarkan oleh guru, kemudian mencatat dan dipaksa untuk menghafalkannya di luar kepala. Keadaan semacam ini jelas akan menghasilkan sikap verbalistik, yang menyebabkan peserta didik menjadi pasif dan kegiatan pembelajaran menjadi cepat menjemukan. Oleh karena itu, 
untuk mengembangkan pembelajaran yang menyenangkan (joyful learning/ joyfull class) serta mengaktifkan siswa, penggu-naan multimedia pembelajaran akan sangat membantu KBM.

Mukminan (2012) menjelaskan bahwa fungsi media dalam kegiatan pembelajaran tidak lagi sekedar peraga bagi guru melainkan pembawa informasi/ pesan pembelajaran yang dibutuhkan siswa. Oleh karena itu, pola interaksi edukatif akan lebih bervariasi hingga meliputi 5 pola berikut: (1). Sumber berupa orang saja (seperti yang kebanyakan terjadi di sekolah kita sekarang); (2). Sumber berupa orang yang dibantu oleh/dengan sumber lain; (3). Sumber berupa orang bersama dengan sumber lain berdasarkan suatu pembagian tanggung jawab; (4). Sumber lain saja tanpa sumber berupa orang; dan (5). Kombinasi dari keempat pola sebelumnya yang terbentuk dalam suatu sistem. Pola interaksi edukatif dapat dilihat pada Gambar 1.

\section{Karakteristik Pembelajaran dengan Multimedia}

Phillips (2009) berpendapat bahwa, karakteristik utama dari pembelajaran dengan multimedia adalah mengintegrasikan berbagai bentuk materi seperti: teks, gambar, grafis, dan suara yang dioperasikan dengan komputer. Lebih lanjut Hamalik (2008) menjelaskan bahwa pembelajaran dengan menggunakan multimedia sangat bermanfaat bagi siswa seperti mendorong rasa ingin tahu siswa, mendorong keinginan untuk mengubah sesuatu yang sudah ada, dan mendorong keinginan siswa untuk mencoba hal-hal yang baru.

Soenarto (2012) menyebutkan karakteristik utama pembelajaran berbasis komputer yaitu: (1) menggunakan fasilitas komputer; (2) dikembangkan berdasarkan kompetensi; (3) strategi pembelajaran yang digunakan meliputi: tutorial, praktik dan dril, pemecahan masalah, permainan, atau simulasi; (4) dikembangkan berdasarkan karakteristik siswa; (5) mengoptimalkan interaksi belajar; fleksibilitas dalam KBM; (7) belajar efektif untuk mempertahankan minat belajar; (8) menyediakan aneka umpan balik dan dapat dilakukan dengan cepat; (9) cocok digunakan untuk berbagai lingkungan belajar; dan (10) menilai kompetensi siswa secara komprehensif dan mendokumentasikan nilai dengan baik.

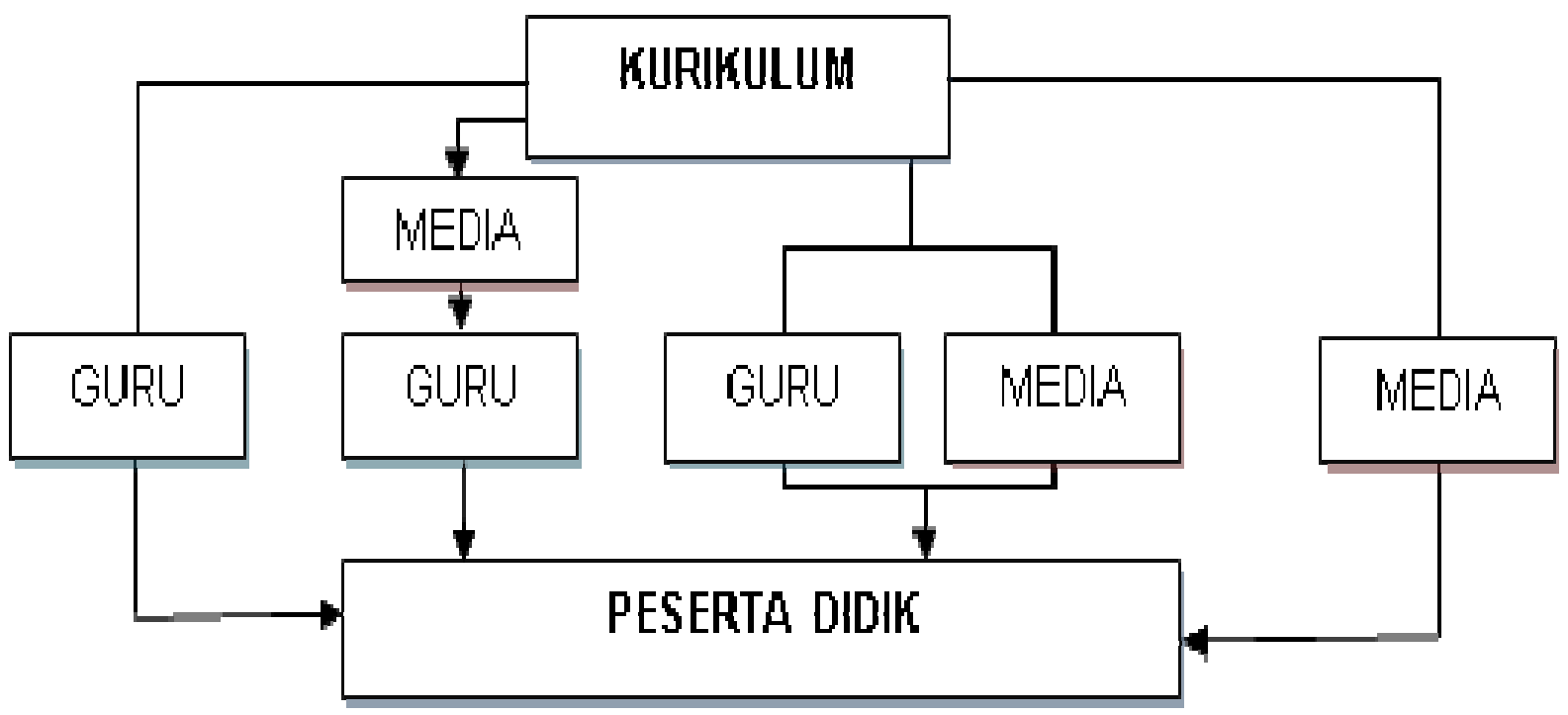

Gambar 1.

Pola interaksi edukatif 


\section{METODE PENELITIAN}

Desain penelitian yang digunakan adalah desk research dengan menggunakan pendekatan kualitatif. Teknik pengumpulan data dengan studi pustaka. Selanjutnya data yang diperoleh dianalisis secara deskriptif. Tahapan analisis data dilakukan dengan mengorganisasikan data, menjabarkan ke dalam unitunit, menyusun ke dalam pola, memilih mana yang penting untuk dipelajari, menguraikan dalam bentuk kata dan kalimat deskriptif. Selanjutnya peneliti menyimpulkan dan memberikan rekomendasi terkait pengembangan dan pemanfaatan multimedia pembelajaran bagi guru dalam KBM.

\section{HASIL DAN PEMBAHASAN}

\section{Pengertian, Peran dan Fungsi Multimedia Interaktif}

Multimedia diartikan bentuk transmisi teks, audio dan grafik dalam periode bersamaan dimaknai sebagai suatu sistem komunikasi interaktif berbasis komputer yang mampu menciptakan, menyimpan, menyajikan dan mengakses kembali informasi berupa teks, grafik, suara, video atau animasi, memungkinkan menyimpan, mengolah dan menyajikan kembali sumber suara dan video dalam format digital. Hal ini sejalan dengan pendapat Schwier \& Misanchuk (2013) yang menyatakan bahwa sedikitnya ada tiga tingkatan yaitu (1) reaktif, (2) proaktif, dan (3) mutual interaksi.

Guru dalam mengembangkan media pembelajaran seharusnya memenuhi kriteria, yakni sesuai kebutuhan usia anak, tepat dalam pemilihan warna dan desainnya, serta media yang interaktif dalam merespon stimulus yang ditampilkan layar monitor komputer. Phillips (2009) menjelaskan makna interaktif sebagai suatu proses pemberdayaan siswa untuk mengendalikan lingkungan belajar. Pengem- bangan media pembelajaran dianggap efektif apabila mampu menumbuhkan minat belajar siswa dan karakteristik siswa.

\section{Komponen dan Model Multimedia Pembelajaran}

Multimedia merupakan suatu sistem komunikasi interaktif berbasis komputer yang mampu menciptakan, menyimpan, menyajikan dan mengakses kembali informasi berupa teks, grafik, suara, video atau animasi (BPMPK, 2014). Lebih lanjut Suyanto (2013) menjelaskan bahwa komponen aplikasi multimedia terdiri dari : graphics, teks, video, sound, dan animasi. Komponen-komponen yang perlu disiapkan untuk mengembangkan multimedia dapat dikelompokkan sebagai berikut: (1). Bahan visual; (2). Bahan audio; dan (3). Permainan dan simulasi.

Media dari bahan-bahan visual tidak memerlukan proyektor untuk melihatnya. Oleh karena itu, media jenis ini relatif banyak digunakan oleh guru-guru. Secara garis besar media ini dapat dibedakan menjadi: (1) Gambar diam menyerupai fotografik yang menggambarkan lokasi, obyek tertentu serta benda-benda; (2). Bahan-bahan grafis adalah bahan-bahan non fotografik dan bersifat dua dimensi yang dirancang untuk mengkomunikasikan suatu pesan kepada siswa. Bahan grafis ini umumnya memuat lambang verbal dan tanda-tanda visual secara simbolis.

Media dari bahan-bahan audio adalah berbagai bentuk/cara perekaman dan transmisi suara (manusia dan suara lainnya) untuk kepentingan tujuan pembelajaran. Media berbasis permainan (game) dicirikan dengan adanya suatu kegiatan dimana para pemain berusaha mencapai tujuan yang ditetapkan dengan mengikuti aturan-aturan yang dipersyaratkan. Sedangkan simulasi (simulation) adalah suatu abstraksi atau penyederhanaan beberapa situasi atau proses kehidupan yang sederhana. 
Teknologi komputer saat ini sudah memungkinkan untuk menyimpan, mengolah dan menyajikan kembali sumber suara dan video dalam format digital. Guru diharapkan mampu mengembangkan media pembelajaran secara simultan yang mampu menampilkan teks, gambar, suara, video atau animasi yang membuat multimedia menjadi interaktif.

\section{Prinsip Pengembangan dan Produksi Multimedia}

Pengembangan media pembela-jaran hendaknya memenuhi prinsip VISUALS (Visible, Interesting, Simple, Useful, Accurate, Legitimate, Structured). Penggunaan media pembelajaran dapat memperlancar proses pembelajaran. Guru diharapkan mampu memilih dan mengembangkan media yang tepat. Contoh membuat media visual dengan memperhatikan langkah dan aspek kajian media dapat dilihat pada Tabel 1 .

\section{Filosofi Pengembangan Multimedia}

Pengembangan multimedia interaktif di dunia pendidikan masih sangat terbatas. Para guru telah mengembangan multimedia berbasis audio, video, power point dalam KBM. Produk-produk multimedia pembelajaran kebanyakan diperoleh di pasaran/toko buku yang tidak relevan dengan karakteristik usia anak. Masih terlihat adanya kelemahan dari model dan paket software aplikasi sehingga pembelajaran interaktif masih belum optimal. Alat bantu belajar baru berupa multimedia interaktif diperlukan agar suatu pembelajaran dapat memberikan hasil optimal serta aktif dan efisien.

Filosofi pengembangan multimedia pembelajaran memiliki 5 komponen yang membentuk hubungan yang sangat erat, menuju satu tujuan yakni memecahkan masalah belajar dan optimalisasi pembeajaran. Teknologi pembelajaran terdiri 5 kawasan (domain) yaitu: 1). Desain, meliputi: desain sistem pembelajaran, desain pesan, strategi pembelajaran, dan analisis karakteristik siswa; 2). Pengembangan, meliputi: teknologi cetak, teknologi audio visual, teknologi komputer, dan teknologi terpadu; 3). Pemanfaatan, meliputi: pemanfaatan media, difusi, inovasi, implementasi dan institusionalisasi, kebijakan dan regulasi; 4). Pengelolaan, meliputi: pengelolaan proyek, pengelolaan sumber belajar dan pengelolaan informasi; dan 5). Evaluasi, meliputi : analisis masalah, pengukuran beracuan kriteria, evaluasi formatif dan sumatif. Kawasan teknologi pembelajaran disajikan pada Gambar 2.

Tabel 1.

Aspek Pembuatan Media Visual

\begin{tabular}{cll}
\hline NO & KONSEP & VISUAL YANG DIPAKAI \\
\hline 1 & Proses dan prosedur & Bagan alur (flowchart) \\
2 & Fakta dan data & Tabel, matriks, dan daftar \\
3 & Data perbandingan & Grafik (balok, cakram, koordinat, kurva) \\
4 & Hubungan ruang & Peta \\
5 & Hubungan dalam struktur & Bagan, skema, diagram \\
6 & Hubungan waktu & Jadwal, Gannt chart \\
7 & Hubungan keluarga & Bagan silsilah \\
\hline
\end{tabular}

Sumber: BPMPK Kemendikbud, 2014 


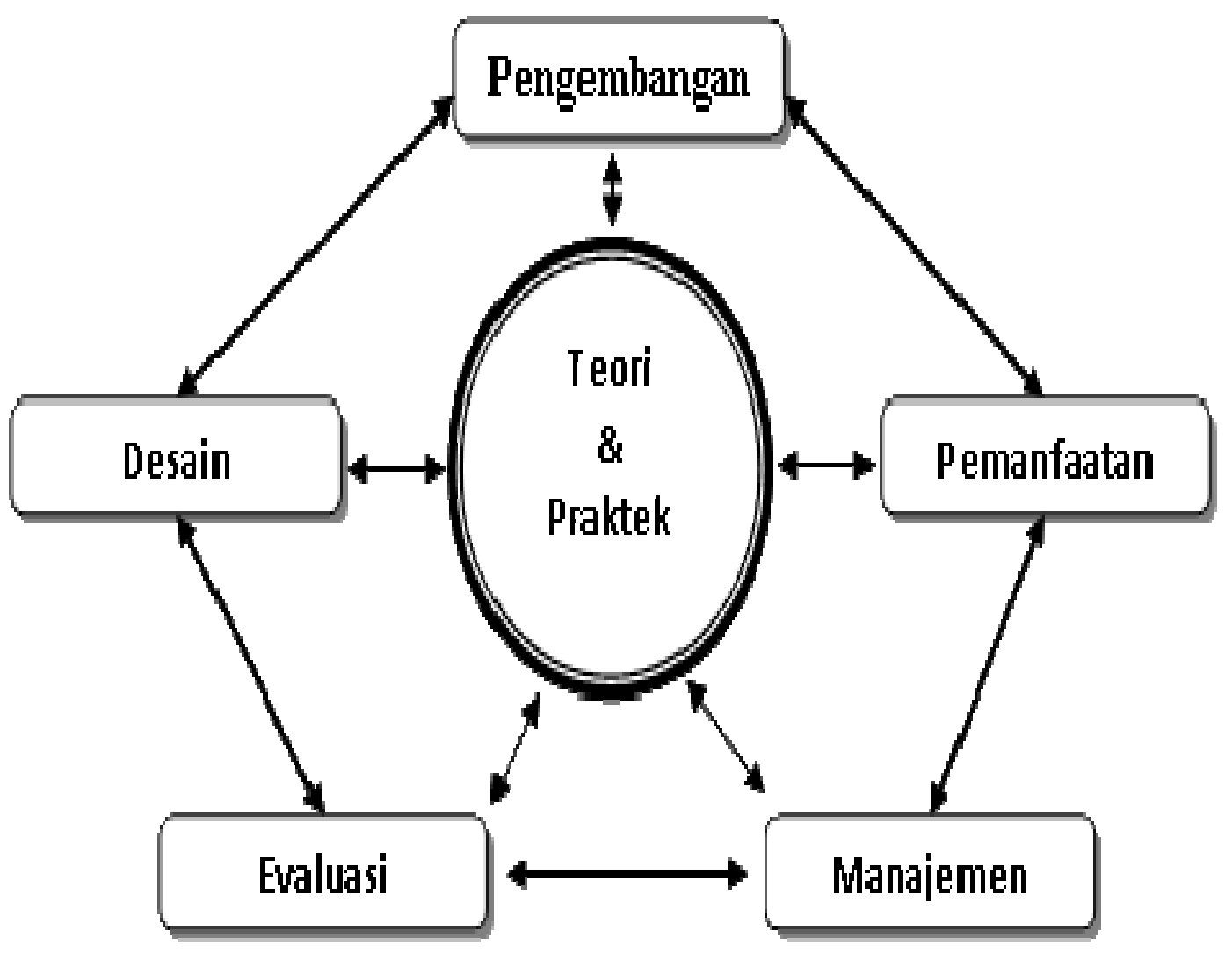

Gambar 2.

Kawasan Teknologi Pembelajaran (Seels \& Richey 2013)

Hubungan antar domain yang ditunjukkan pada Gambar 2 tidaklah linier. Namun dengan menggunakan gambar tersebut diharapkan menjadi lebih mudah untuk memahami bagai-mana domain itu saling melengkapi pada saat daerah penelitian dan teori dalam setiap domain disajikan. Ilustrasi pada Gambar 2 meringkas daerah utama dalam dasar pengetahuan untuk setiap dominan.

Bentuk sistem multimedia yang pada saat ini banyak digunakan di kelas bukan parsial/terpisah, namun dalam kombinasi multimedia dalam bentuk satu kit yang disatukan. Satu perangkat multimedia adalah suatu gabungan bahan pembelajaran yang meliputi lebih dari satu jenis media dan disusun atau digabungkan berdasarkan atas satu topik tertentu. Perangkat ini dapat mencakup slide, film rangkai, pita suara, piringan hitam, gambar diam, grafik, transparansi, peta, buku kerja, chart, dan lain- lain menjadi satu model. Misalnya penggunaan komputer untuk program power point, CD untuk pembelajaran, maupun piranti mobile.

Konsep multimedia bukan sekadar penggunaan media secara majemuk untuk pencapaian kompetensi tertentu, namun mencakup pengertian perlunya integrasi masing-masing media yang digunakan dalam suatu penyajian yang tersusun secara baik (sistemik dan sistematik). Masing-masing media dalam sistem multimedia ini dirancang untuk saling melengkapi sehingga secara keseluruhan media yang digunakan akan menjadi lebih besar peranannya.

\section{Pemanfaatan Multimedia dalam Kegiatan Pembelajaran}

Apabila guru mampu dalam memanfaatkan multimedia pembelajaran dengan benar, maka akan sangat membantu efektifitas 
proses pembelajaran serta penyampaian pesan dan isi pelajaran sehingga dapat membantu siswa meningkatkan pemahaman karena menyajikan informasi secara menarik dan terpercaya. Selain itu media pembelajaran juga dapat memudahkan penafsiran data dan memadatkan informasi. Hal ini memungkinkan tercapainya tujuan pembelajaran, yang pada akhirnya dapat meningkatkan minat dan hasil belajar. Sebagaimana pendapat Arsyad (2002) pemakaian media pembelajaran dalam proses belajar mengajar dapat membangkitkan keinginan dan minat yang baru, membangkitkan motivasi dan rangsangan kegiatan pembelajaran dan bahkan membawa pengaruhpengaruh psikologis terhadap siswa.

Hasil belajar yang optimal akan diperoleh melalui pemanfaatan media pembelajaran dengan benar. Pernyatan tersebut sesuai dengan Phillips (2009), Hamalik (2008), maupun Soenarto (2012). Pemanfaatan multimedia dalam pembelajaran memiliki aspek kelebihan, antara lain: (1) memungkinkan terjadinya interaksi siswa dan materi pelajaran; (2) proses belajar secara individual sesuai kemampuan siswa; (3) menampilkan unsur audiovisual dan langsung memberikan umpan balik; dan (4) menciptakan proses belajar yang berkesinambungan. Oleh karena itu, guru harus selalu membekali diri dengan skill pengembangan dan pemanfaatan media pembelajaran dengan benar agar hasil pembelajaran lebih optimal.

\section{KESIMPULAN DAN SARAN}

\section{Kesimpulan}

Media adalah perantara atau pengantar pesan dari pengirim kepada penerima pesan. Sedangkan yang dimaksud media pembelajaran adalah media yang digunakan untuk menyampaikan pesan dengan tujuan-tujuan pembelajaran. Fungsi media dalam kegiatan pembelajaran tidak lagi sekedar peraga bagi guru melainkan pembawa informasi/pesan pembelajaran yang dibu-tuhkan siswa. Prinsip pengembangan media pembelajaran hendaknya memenuhi prinsip VISUALS (Visible, Interesting, Simple, Useful, Accurate, Legitimate, Structured).

Karakteristik utama pembelajaran berbasis komputer, antara lain: (1) menggunakan fasilitas komputer; (2) dikembangkan berdasarkan kompetensi, ; (3) strategi pembelajaran yang digunakan meliputi: tutorial, praktik dan dril, pemecahan masalah, permainan, atau simulasi; (4) dikembangkan berdasarkan karakteristik siswa; (5) mengoptimalkan interaksi belajar siswa; (6) memiliki fleksibilitas dalam mengatur kegiatan belajar; (7) Belajar efektif untuk mempertahankan minat belajar; (8) menyediakan aneka umpan balik dan dapat dilakukan dengan cepat; (9) cocok digunakan untuk berbagai lingkungan belajar; dan (10) menilai kompetensi siswa secara komprehensif dan mendokumentasikan nilai dengan baik. Landasan pengembangan dan pemanfaatan multi media pembelajaran, setidaknya mempertimbangkan 5 domain meliputi; desain, pengembangan, pemanfaatan, pengelolaan, dan evaluasi.

\section{Saran}

Peran dan fungsi media pembelajaran begitu signifikan dalam keberhasilan suatau pembelajaran. Oleh karena itu sebaiknya guru sebagai pengguna hendaknya memahami tentang konsep dan pengembangan media pembelajaran, agar informasi/materi ajar dapat tersampaikan secara maksimal dengan keberhasilan pembelajaran siswa. Karakteristik pengembangan pembelajaran yang sebaiknya dipahami oleh guru/ pengembang media, antara lain: (1). Biaya murah, baik pada saat pembuatan maupun pemeliharaan; (2). Kesesuaiannya dengan metode pembelajaran; (3). Kesesuaian dengan karakteristik/kuri- 
kulum peserta didik; (4). Pertimbangan praktis meliputi kemudahannya dipindahkan atau ditempatkan, kesesuaian dengan fasilitas yang ada di kelas, keamanan penggunaannya, daya tahannya, dan kemudahan perbaikannya; (5). Ketersediaan bahan pendukung media yang dikembangkan; (6). Mempermudah, menyederhanakan, dan mempercepat keberlangsungan proses belajar mengajar; (7). Penyajian pesan materi pembelajaran; (8). Dirancang secara sistematis sesuai dengan tingkat kemampuan dan alokasi waktu.

Landasan pengembangan dan pemanfaatan multimedia pembelajaran sebaiknya tidak hanya berlandaskan 5 aspek/domain, namun juga bisa mempertimbangkan hal-hal lain seperti, berpusat pada potensi anak; perkembangan anak; kebutuhan anak; dan kepentingan peserta didik serta lingkungannya yang menyeluruh dan berkesinambungan.

\section{DAFTAR PUSTAKA}

Arsyad, A. (2012). Media Pembelajaran. Jakarta: PT. Raja Grafindo Persada.

Balai Pengembangan Multimedia Pembelajaran dan Kebudayaan Kemendikbud. (2014). Karakteristik Media Pembelajaran. Semarang: BPMPK Pustekkom Kemendikbud.

Hamalik. (2008). Proses Belajar Mengajar. Bandung: Bumi Aksara.

Heinich, R., Molenda, M., Russel, J. D. (2010). Instructional Media: and the New Technology of Instruction, New York: Jonh Wily and Sons.

Latuheru, J. D. (2012). Media Pembelajaran dalam Proses Belajar-Mengajar Masa Kini. Jakarta: Depdikbud.

Miarso, Y. (2010). Menyemai Benih Teknologi Pendidikan. Yogyakarta: Pustaka Pelajar
Mukminan. (2012). Desain Pembelajaran. Yogyakarta: FPIPS IKIP Yogyakarta Press.

Phillips, R. (2009). The Developer's Handbooks to Interactive Multimedia: A Practice Guide for Educational Applications, London: Kogan Page Limited.

Prastati, T. Irawan, P. (2010). Media Sederhana. Jakarta: PAU-PPAI.

Sadiman, A. S., Rahardjo, R., Haryono, A., Harjito. (2012). Media pendidikan, pengertian, pengembangan dan pemanfatannya. Jakarta: CV. Rajawali.

Schwier, R., Misanchuk, E. (2013). Interactive multimedia instruction. Englewood Cliffs, NJ: Educational Technology Publications.

Seels, B. B., Richey R.C. (2013). Instructional Technology: The Defenition and Domains of The Field. AECTWashington, DC.

Soenarto, S. (2012). Pembelajaran Berbasis Multimedia sebagai Upaya Meningkatkan Kompetensi Hasil Belajar dan Persepsi Mahasiswa. Yogyakarta: Cakrawala Pendidikan Universitas Negeri Yogyakarta.

Suryo. (2013). Struktur dan Desain Rumbel. Makalah disampaikan pada lokakarya Penyusunan desain sistem aplikasi mobile pada tanggal 01 s.d. 04 Desember 2013 di Semarang.

Suyanto, M. (2013). Multimedia Alat untuk Meningkatkan Keunggulan Bersaing. Yogyakarta: Penerbit Andi Yogyakarta.

Walter, D., Carrey, L., Carey, J. O. (2005). The Systematic Design of Instruction. Boston: Pearson, Allyn and Bacon. 


\section{BIODATA PENULIS}

Mohamad Miftah, lahir 20 Desember 1977 di Kabupaten Demak. Magister Teknologi Pembelajaran dari Universitas Negeri Yogyakarta. Saat ini sedang menempuh studi doktoral pada program studi Manajemen Kependidikan PPs, Universitas Negeri Semarang (UNNES). Sekarang bekerja di Bappeda Propinsi Jawa Tengah sebagai Peneliti Madya. 